\title{
Expression and immunogenicity of NY-ESO-1 in colorectal cancer
}

\author{
YA LI $^{1 *}$, RUIFENG SONG ${ }^{1 *}$, XINQIANG LI $^{2}$ and FENG XU ${ }^{1}$ \\ Departments of ${ }^{1}$ Gastroenterology and ${ }^{2}$ Pathology, \\ The First Affiliated Hospital of Zhengzhou University, Zhengzhou, Henan 450052, P.R. China
}

Received January 24, 2016; Accepted January 26, 2017

DOI: $10.3892 /$ etm.2017.4405

\begin{abstract}
Serum assays of NY-ESO-1 antibodies provide a guide to discriminate between patients who suffer from different types of cancer. In the present study, the expression of NY-ESO-1 was detected with the aim to identify a novel tumor antigen in colorectal cancer (CRC). Sera were obtained from 89 healthy individuals and 236 patients with CRC with stage I, II, III and IV tumors. The NY-ESO-1 autoantibody levels were determined using an enzyme-linked immunosorbent assay. The mRNA and protein expression levels of NY-ESO-1 were detected using reverse transcription-polymerase chain reaction and immunohistochemistry, respectively, in $60 \mathrm{CRC}$ and paired adjacent non-tumor tissues. NY-ESO-1 antibody was detected in 40 of the $236(16.9 \%)$ patients with CRC. The NY-ESO-1 antibody combined with carcinoembryonic antigen enhanced the sensitivity, from 52.1 to $62.7 \%$, of the diagnosis of CRC. The frequency of antibody positivity increased with the TNM cancer stage (8.8 vs. $28.3 \%$ in stages I+II and III+IV, respectively). The mRNA and protein expression levels of NY-ESO-1 were significantly higher in CRC tissue than in adjacent non-tumor tissue. In conclusion, NY-ESO-1 is frequently expressed in CRC with the capacity of inducing a humoral immune response in CRC patients, exhibiting the potential to be a promising biomarker for CRC.
\end{abstract}

\section{Introduction}

Colorectal cancer (CRC) is one of the most common types of cancer in the world (1). The prognosis of CRC depends on the stage at diagnosis, thus early detection of CRC has great potential to reduce the mortality of the disease (2). It

Correspondence to: Professor Feng Xu, Department of Gastroenterology, The First Affiliated Hospital of Zhengzhou University, 1 Jianshe Road, Zhengzhou, Henan 450052, P.R. China E-mail: xufengmd@sina.com

\section{*Contributed equally}

Key words: NY-ESO-1, colorectal cancer, enzyme-linked immunosorbent assay is of critical importance to improve the understanding of the pathogenesis of CRC, as well as to identify reliable biomarkers for CRC diagnosis and prognosis. The detection of serological biomarkers is used for CRC screening as it is convenient and relatively non-invasive; however, the effective clinical application of the majority of blood biomarkers is impeded by low detection sensitivity (3). For example, carcinoem bryonic antigen (CEA) is widely accepted as a blood biomarker associated with CRC; however, the overall sensitivity for CEA detection in CRC varies between 43 and 69\% (4).

Cancer testis (CT) antigens are a group of tumor antigens that may elicit the immune system during tumorigenesis. One of the most common characteristics of CT antigens is their aberrant expression in multiple tumors and their absence in normal tissues, apart from in the testes and ovaries. As one of the most important CT antigens, NY-ESO-1 has attracted considerable attention due to the marked cellular and humoral immune responses it induces (5). NY-ESO-1 autoantibody is often detected in patients with NY-ESO-1-positive esophageal (6), lung (7,8), breast (9), gastric (10) and hepatocellular (11) cancer. Therefore, NY-ESO-1 may be a valuable serological biomarker and provide a specific immunotherapeutic method for these types of cancer.

It is currently understood that NY-ESO-1-specific antibodies are more highly expressed in the advanced stages of CRC (12); however, knowledge about the expression of NY-ESO-1 in the CRC tissues, and the serological expression in early CRC, is lacking. The present study aimed to evaluate the mRNA and protein expression levels of NY-ESO-1 in CRC tissues, and the levels of NY-ESO-1 autoantibody in CRC patients according to the tumor stage.

\section{Materials and methods}

Ethics statement. The experimental protocols of the present study were approved by the Ethics Committee of Zhengzhou University (Zhengzhou, China). Written informed consent was provided by all participants.

Serum sample and tissue specimen collection from CRC patients. A total of 236 patients with histologically confirmed CRC were enrolled in the present study. Serum samples were obtained from all 236 patients hospitalized in the Department of Gastrointestinal Surgery at The First Affiliated Hospital of 
Zhengzhou University (Zhengzhou, China) for surgical treatment and/or chemotherapy in the period between March 2013 and January 2015. CRC tumor stage was determined according to the TNM classification of the Union for International Cancer Control (13). Fixed and frozen tumor and adjacent non-tumor tissue specimens were obtained from 60 out of 236 patients during surgery. Clinical parameters and CEA values were gained from the medical records. Patients who suffered from autoimmune diseases or who had been taking immunosuppressive medication were excluded from the present study. Serum samples were provided by 89 healthy donors to be used as controls. All sera were extracted and stored at $-80^{\circ} \mathrm{C}$.

Enzyme-linked immunosorbent assay (ELISA). Serum samples were analyzed for the expression of NY-ESO-1 antibody using ELISA. NY-ESO-1 recombinant protein (cat. no. LS-G19931; Lifespan Bioscience, Seattle, WA, USA) was diluted in phosphate-buffered saline (PBS) to a final concentration of $1 \mu \mathrm{g} / \mathrm{ml}$ and subsequently coated onto 96-well plates (Corning Inc., Corning, NY, USA), which were then incubated overnight at $4^{\circ} \mathrm{C}$. Following this, the plates were washed with PBS twice and blocked with $200 \mu \mathrm{l} 5 \%$ fetal bovine serum in PBS for $1 \mathrm{~h}$ at room temperature. Subsequently, the plates were washed with PBS twice and $100 \mu 1$ serum dilutions were added and the plates were incubated for $2 \mathrm{~h}$ at room temperature. After washing twice with PBS, horseradish peroxidase-conjugated rabbit anti-human immunoglobulin G (cat. no. A019002; Dako, Glostrup, Denmark) was added as a secondary antibody, and the plates were incubated for $1 \mathrm{~h}$ at room temperature. Following this, the plates were incubated for $30 \mathrm{~min}$ at room temperature with the substrate, 3,3',5,5'-tetramethylbenzidine (cat. no. 860336; Sigma Aldrich; Merck Millipore, Darmstadt, Germany) and absorbance was read at $450 \mathrm{~nm}$ using an ELISA reader (Bio-Rad Laboratories, Inc., Hercules, CA, USA). Bovine serum albumin (Gibco; Thermo Fisher Scientific, Inc., Waltham, MA, USA) was used as a control protein. Levels of NY-ESO-1 $\mathrm{Ab}$ were defined by relative optical density (OD) values.

Reverse transcription-polymerase chain reaction (RT-PCR). RNA was extracted from frozen CRC and adjacent non-tumor tissue using TRIzol reagent (Invitrogen; Thermo Fisher Scientific, Inc.). Total RNA was reverse transcribed by using a reverse transcription system kit (cat. no. A3500; Promega Corp., Madison, WI, USA) according to the manufacture's protocol. The PCR primers were designed using Primer 5.0 design software (Primer Biosoft, Palo Alto, CA, USA). The sequences of the primers used were as follows: 5'-AGACGT CGTAGGTAAGTCGGGAC-3' and 5'-GGAGGGAGTCCC GTCTCCGCG-3' for NY-ESO-1, and 5'-ACCACAGTCCAT GCCATCAC-3' and 5'-TCCACCACCCTGTTGCTGTA-3' for GAPDH. DNase was used to remove genomic DNA. Products were amplified by PCR using a Taq 2X PCR Master Mix (cat. no. KT201; Tiangen Biotech Co., Ltd., Beijing, China). A $25 \mu 1$ reaction containing template $(1 \mu \mathrm{l})$, primer $(2 \mu \mathrm{l})$, Taq $2 \mathrm{X}$ PCR Master Mix (12.5 $\mu \mathrm{l})$ and double-distilled $\mathrm{H}_{2} \mathrm{O}$ was produced and PCR was performed under the following conditions: Initial denaturation at $94^{\circ} \mathrm{C}$ for $3 \mathrm{~min}$, followed by 30 cycles of $94^{\circ} \mathrm{C}$ for $30 \mathrm{sec}, 60^{\circ} \mathrm{C}$ for $45 \mathrm{sec}$ and $72^{\circ} \mathrm{C}$ for $45 \mathrm{sec}$, and a final extension step of $72^{\circ} \mathrm{C}$ for $5 \mathrm{~min}$. The size and quantity of the PCR products were verified by electrophoresis on $1.5 \%$ agarose gel stained with ethidium bromide. Relative mRNA expression levels were evaluated using the band intensity ratio of the target gene to GADPH. All PCR reactions were performed in triplicate. Densitometric analysis was performed using Tanon Image software 2500 (Tanon Science and Technology Co., Ltd., Shanghai, China).

Immunohistochemistry (IHC). Specimens were fixed with formalin and embedded in paraffin. The samples were cut into 4- $\mu \mathrm{m}$ thick slices and used for immunohistochemical analyses. The slices were incubated in $0.3 \%$ hydrogen peroxide for $30 \mathrm{~min}$ at room temperature, blocked with $10 \%$ normal goat serum for $30 \mathrm{~min}$ at room temperature and incubated with a primary NY-ESO-1 monoclonal antibody (1:200; cat. no. 356200; Thermo Fisher Scientific, Inc.) overnight at $4{ }^{\circ} \mathrm{C}$. Following this, the slices were applied for $30 \mathrm{~min}$ at room temperature with a biotin-conjugated secondary antibody (1:50; cat. no. K346711; Dako). A DAB kit (Dako) was used for staining. The slides were subsequently counterstained with hematoxylin and a cover slip was placed over them. Normal adult testis tissue was used as a positive control. Incubation samples of same procedures omitting the primary antibody were used as negative controls.

CEA detection. Serum CEA levels were detected at the clinical laboratory department of The First Affiliated Hospital of Zhengzhou University. CEA positivity was defined as serum levels of CEA $>5.0 \mathrm{ng} / \mathrm{ml}$.

Statistical analysis. Statistical analysis was performed using SPSS v. 18.0 software (SPSS, Inc., Chicago, IL, USA). Significant differences between groups were assessed using $\chi^{2}$ and Fisher's exact tests. $\mathrm{P}<0.05$ was considered to indicate a statistically significant difference.

\section{Results}

Antibody response to NY-ESO-1 combined with CEA. A total of 236 CRC patient sera and 89 healthy control sera were tested with ELISA to detect NY-ESO-1 humoral immune response positivity. In the control subjects, the mean OD value was 0.312 , with a standard deviation (SD) of 0.147 . The mean $\mathrm{OD}+3 \mathrm{SD}$ of the healthy control sera was used as the cut-off point for positivity for NY-ESO-1 antibodies. Consequently, the NY-ESO-1 response positivity was defined as an OD value of $>0.75$. The prevalence of antibodies against NY-ESO- 1 was $16.9 \%$ in patients with CRC (40 of 236), compared with $2.2 \%$ in healthy control subjects ( 2 of 89 ). The relationship between antibodies against NY-ESO-1 and CEA was also investigated. In the CRC patients, $52.1 \%$ (123 of 236) were positive for CEA. The sensitivity of CRC diagnosis was significantly increased to $62.7 \%$ (148 of 236) following the combined detection of antibodies against NY-ESO- 1 and CEA compared with CEA only $(\mathrm{P}=0.020)$ and NY-ESO-1 only $(\mathrm{P}<0.001 ;$ Fig. 1$)$.

Correlation between antibodies against NY-ESO-1 and the clinicopathological parameters in CRC. The potential correlation between NY-ESO-1 antibody expression and the clinicopathological parameters in CRC was investigated (Table I). It was demonstrated that the NY-ESO-1 antibody positivity was significantly correlated with tumor progression, such 
Table I. Association between NY-ESO-1 antibody positivity and clinicopathological parameters of colorectal cancer.

\begin{tabular}{|c|c|c|c|}
\hline Parameter & $\begin{array}{l}\text { Positive for } \\
\text { NY-ESO-1 } \\
\text { antibody }^{\mathrm{a}}\end{array}$ & $\begin{array}{c}\text { Negative for } \\
\text { NY-ESO-1 } \\
\text { antibody }^{\mathrm{a}}\end{array}$ & P-value \\
\hline \multicolumn{4}{|l|}{ Gender } \\
\hline Male & $21(14.8)$ & $121(85.2)$ & \multirow[t]{2}{*}{0.277} \\
\hline Female & $19(20.2)$ & $75(79.8)$ & \\
\hline \multicolumn{4}{|l|}{ Age, years } \\
\hline$\leq 60$ & $15(17.6)$ & $70(82.4)$ & \multirow[t]{2}{*}{0.830} \\
\hline$>60$ & $25(16.6)$ & $126(83.4)$ & \\
\hline \multicolumn{4}{|l|}{ Tumor location } \\
\hline Colon & $28(19.7)$ & $114(81.3)$ & \multirow[t]{2}{*}{0.163} \\
\hline Rectum & $12(12.8)$ & $82(87.2)$ & \\
\hline \multicolumn{4}{|l|}{$\begin{array}{l}\text { Depth of tumor } \\
\text { invasion }\end{array}$} \\
\hline $\mathrm{T} 1-\mathrm{T} 2$ & $14(9.9)$ & $127(90.1)$ & \multirow[t]{2}{*}{0.001} \\
\hline T3-T4 & $26(27.4)$ & $69(72.6)$ & \\
\hline \multicolumn{4}{|l|}{$\begin{array}{l}\text { Lymph node } \\
\text { metastasis }\end{array}$} \\
\hline Negative & $6(4.1)$ & 139 (95.9) & \multirow[t]{2}{*}{$<0.001$} \\
\hline Positive & $34(37.4)$ & $57(62.6)$ & \\
\hline \multicolumn{4}{|l|}{ Distant metastasis } \\
\hline Negative & $26(14.1)$ & $158(85.9)$ & \multirow[t]{2}{*}{0.030} \\
\hline Positive & $14(26.9)$ & $38(73.1)$ & \\
\hline \multicolumn{4}{|l|}{ TNM stage } \\
\hline $\mathrm{I}+\mathrm{II}$ & $12(8.8)$ & $125(91.2)$ & \multirow[t]{2}{*}{$<0.001$} \\
\hline III+IV & $28(28.3)$ & $71(71.7)$ & \\
\hline \multicolumn{4}{|l|}{ Histological type } \\
\hline Differentiated & $25(18.9)$ & $107(81.1)$ & \multirow[t]{2}{*}{0.359} \\
\hline Undifferentiated & $15(14.4)$ & $89(85.6)$ & \\
\hline
\end{tabular}

${ }^{a}$ Data are presented as $\mathrm{N}(\%)$.

as depth of tumor invasion, lymph node and distant metastasis $(\mathrm{P}=0.001, \mathrm{P}<0.001$ and $\mathrm{P}=0.03$, respectively; Table $\mathrm{I})$. However, NY-ESO-1 antibody positivity demonstrated no significant correlation with sex, age, location and histological type.

The correlation between NY-ESO-1 antibody positivity and tumor stage is demonstrated in Fig. 2. The positive rates of antibodies against NY-ESO-1 in CRC patients increased from $6.3 \%$ in stage I tumors to $11,23.1$ and $34 \%$ in stage II, III and IV tumors, respectively.

NY-ESO-1 mRNA expression levels. The expression level of NY-ESO-1 mRNA in CRC patients was analyzed using RT-PCR. NY-ESO-1 mRNA expression was detected in $21.7 \%$ (13 of 60 ) tumor specimens. No NY-ESO-1 mRNA was detected in the 60 adjacent non-tumor tissues (Fig. 3).

Immunohistochemical staining. NY-ESO-1 protein was expressed in cancer cells; however, it was not expressed in adjacent non-tumor tissues. NY-ESO-1 protein was detected

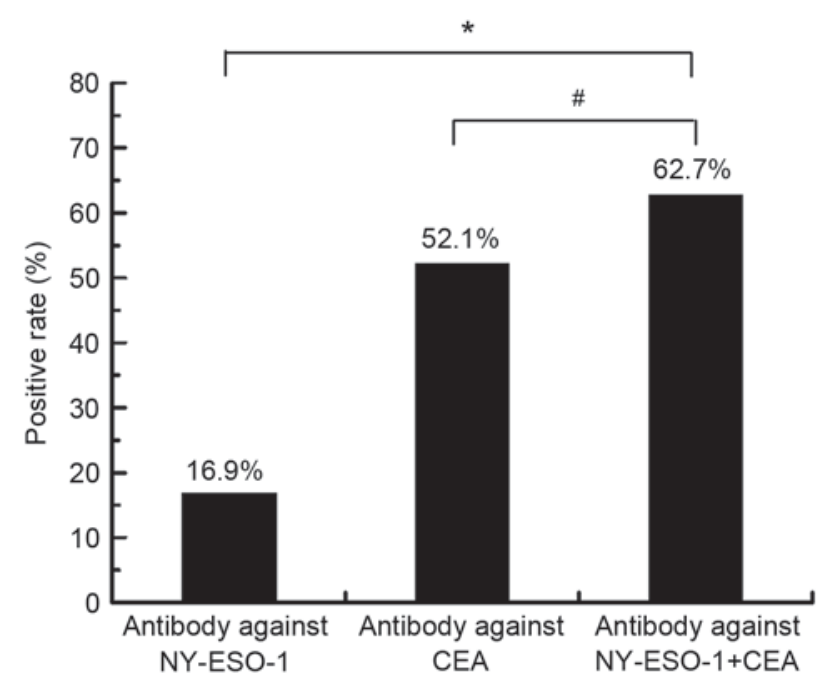

Figure 1. Positive rate of antibodies against NY-ESO-1 and CEA in patients with colorectal cancer. " $\mathrm{P}<0.001$ vs. NY-ESO-1 only; $\mathrm{P}=0.02$ vs. CEA only. CEA, carcinoembryonic antigen.

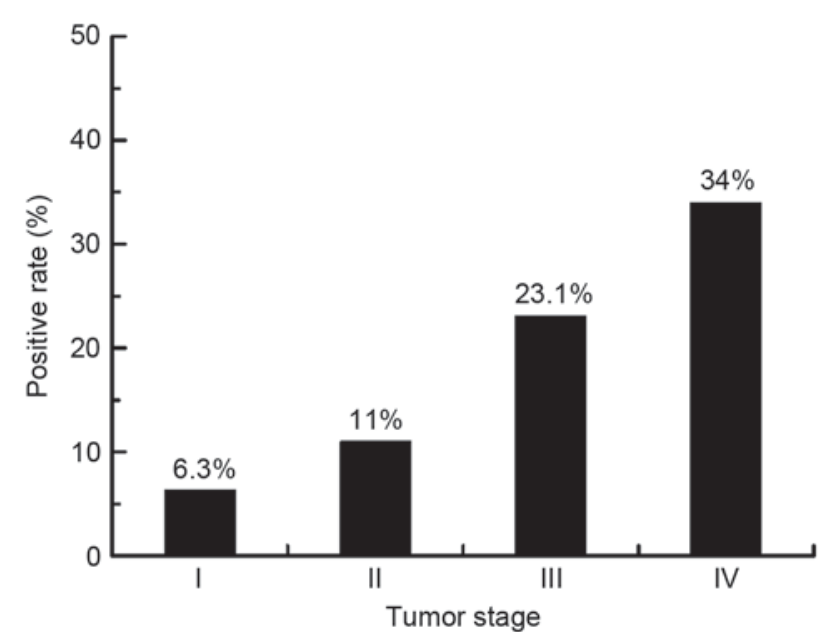

Figure 2. Positive rate of antibodies against NY-ESO-1 in colorectal cancer patients according to tumor stage.

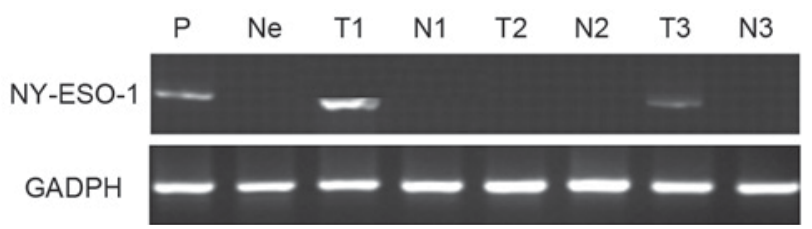

Figure 3. NY-ESO-1 mRNA expression levels in CRC tissues, as determined by reverse transcription-polymerase chain reaction. GADPH was used as an internal control. T, CRC tissue; $\mathrm{N}$, paired adjacent non-tumor tissue; $\mathrm{P}$, positive control (testis); $\mathrm{Ne}$, negative control (no cDNA).

in $26.7 \%$ (16 of 60) of CRC patients and was located in the cytoplasm of cancer cells (Fig. 4).

\section{Discussion}

Based on the fact that CT antigens are able to elicit cellular as well as humoral immune responses, it is understood that cancer cells may be recognized and killed by the immune 

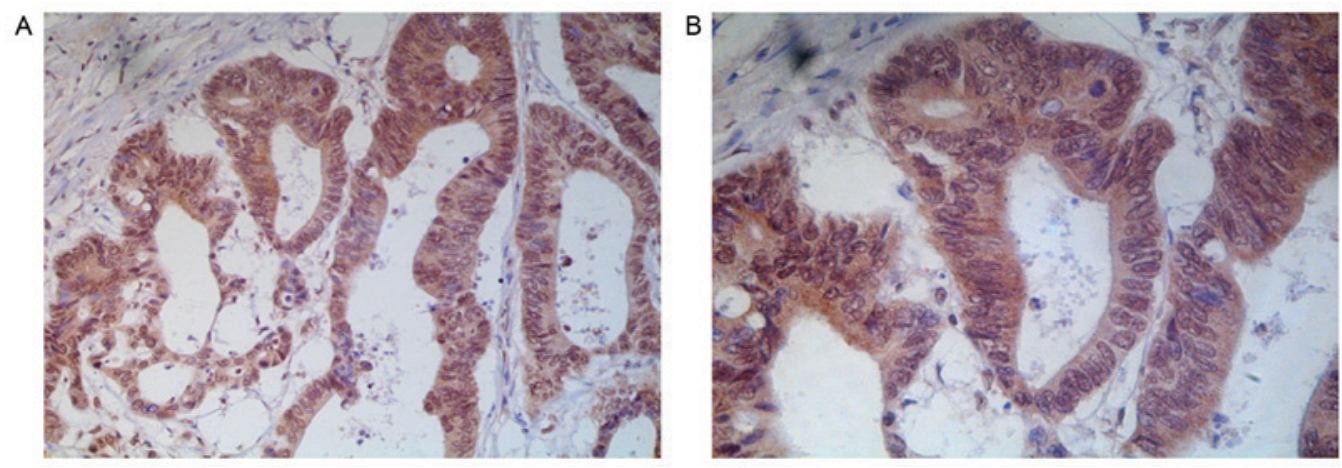

Figure 4. Immunohistochemical staining (hematoxylin) of NY-ESO-1 in colorectal cancer tissues at magnification (A) x200 and (B) x400.

system (14). CT gene products represent attractive targets for cancer immunotherapy, and they are believed to be a promising therapeutic candidate for the treatment of many tumor types. One of the major barriers to antigen-specific immunotherapy in CRC is the lack of definite immunogenic tumor antigens. There is an urgent requirement for the identification of new targets for immunotherapy for CRC. NY-ESO-1 is a classic CT antigen, which was discovered during a SEREX analysis of esophageal cancer (15). The expression of NY-ESO-1 antibody has been reported in a wide variety of cancer types; however, it has not been detected in normal tissue (16-18). Therefore, NY-ESO-1 antibody represents an ideal target for antigen-specific immunotherapy. Furthermore, due to the expression characteristics of NY-ESO-1, it is considered to be a potential diagnostic marker for various cancer types $(10,19)$.

The present study detected NY-ESO-1 antibody in $16.9 \%$ of CRC sera. This was not consistent with previous reports $(20,12)$. These differences may have been caused by the sample size and the different cancer stage of patients. Furthermore, in the present study, the combination of NY-ESO-1 and CEA antibodies as tumor markers increased the rate of tumor detection from 52.1 to $62.7 \%$. The measurement of CEA levels is commonly used to assess the prognosis of CRC patients. The expression of NY-ESO-1 is restricted to tumor tissues and NY-ESO-1 antibody is only detectable in patients with NY-ESO-1-expressing tumors (21). Due to the highly specific expression of NY-ESO-1, the detection of NY-ESO-1 antibody may be used for diagnosing malignancy. From the present study, it may be considered that NY-ESO-1 antibody has potential clinical application as a novel biomarker in combination with CEA for CRC detection.

Due to NY-ESO-1 antibody being expressed in CRC, the present study investigated the possible relationship between NY-ESO-1 antibody expression and the clinicopathological parameters of CRC. Results suggested that NY-ESO-1 antibody expression was significantly correlated with depth of tumor invasion, lymph node metastasis and distant metastasis in CRC, irrespective of age, sex, location and histological type. The positive rates of serum NY-ESO-1 antibodies in patients with CRC gradually increased according to the tumor stage. NY-ESO-1 antibody expression had a higher frequency in TNM stage III and IV tumors (28.3\%) than in stage I and II tumors (8.8\%). TNM stage is one of the most essential prognostic factors in CRC $(22,23)$. The critical correlation between NY-ESO-1 antibody expression and TNM stage may indicate that NY-ESO-1 antibody expression is a poor prognostic factor. In contrast, due to the antibody and $\mathrm{T}$ cell responses induced in CRC $(20,12)$, NY-ESO-1 antibody expression may favor the prognosis of the patients with advanced TNM stages. Therefore, the relationship between NY-ESO-1 antibody expression and prognosis remains unclear and additional investigation is required to increase the understanding of this relationship.

In the present study, a higher number of NY-ESO-1-positive tissue was detected by IHC than by RT-PCR (16 vs. 13 out of 60 , respectively). The inconsistency between tissue and serum antibody expression may be attributed to the limited number of tumor specimens. Extensive RT-PCR and IHC analysis should be employed to analyze the relationship between NY-ESO-1 expression levels and the clinicopathological parameters of CRC.

In conclusion, the present study demonstrated that NY-ESO-1 and NY-ESO-1 antibody are expressed in patients with CRC. Therefore, NY-ESO-1, as with other important CT antigens, may be used as a serum biomarker in combination with other conventional serum tumor markers in CRC diagnosis. The association between NY-ESO-1 antibody and immunogenicity means that the NY-ESO-1 antibody may be used as an alternative biomarker for vaccine treatments in subsequent research.

\section{Acknowledgements}

The present study was supported by the Youth Innovation Fund of The First Affiliated Hospital of Zhengzhou University.

\section{References}

1. Jemal A, Bray F, Center MM, Ferlay J, Ward E and Forman D: Global cancer statistics, CA Cancer J Clin 61: 69-90, 2011.

2. Walsh JM and Terdiman JP: Colorectal cancer screening: Scientific review. JAMA 289: 1288-1296, 2003.

3. Hundt S, Haug U and Brenner H: Blood markers for early detection of colorectal cancer: A systematic review. Cancer Epidemiol Biomarkers Prev 16: 1935-1953, 2007.

4. Blake KE, Dalbow MH, Concannon JP, Hodgson SE, Brodmerkel GJ Jr, Panahandeh AH, Zimmerman K and Headings JJ: Clinical significance of the preoperative plasma carcinoembryonic antigen (CEA) level in patients with carcinoma of the large bowel. Dis Colon Rectum 25: 24-32, 1982.

5. Jäger E, Chen YT, Drijfhout JW, Karbach J, Ringhoffer M, Jäger D, Arand M, Wada H, Noguchi Y, Stockert E, et al: Simultaneous humoral and cellular immune response against cancer-testis antigen NY-ESO-1: Definition of human histocompatibility leukocyte antigen (HLA)-A2-binding peptide epitopes. J Exp Med 187: 265-270, 1998. 
6. Xu YW, Peng YH, Chen B, Wu ZY, Wu JY, Shen JH, Zheng CP, Wang SH, Guo HP, Li EM and Xu LY: Autoantibodies as potential biomarkers for the early detection of esophageal squamous cell carcinoma. Am J Gastroenterol 109: 36-45, 2014.

7. Shan Q, Lou X, Xiao T, Zhang J, Sun H, Gao Y, Cheng S, Wu L, $\mathrm{Xu} \mathrm{N}$ and Liu S: A cancer/testis antigen microarray to screen autoantibody biomarkers of non-small cell lung cancer. Cancer Lett 328: 160-167, 2013.

8. Healey GF, Lam S, Boyle P, Hamilton-Fairley G, Peek LJ and Robertson JF: Signal stratification of autoantibody levels in serum samples and its application to the early detection of lung cancer. J Thorac Dis 5: 618-625, 2013.

9. Yang Z, Chevolot Y, Géhin T, Solassol J, Mange A, Souteyrand E and Laurenceau E: Improvement of protein immobilization for the elaboration of tumor-associated antigen microarrays: Application to the sensitive and specific detection of tumor markers from breast cancer sera. Biosens Bioelectron 40: 385-392, 2013

10. Fujiwara S, Wada H, Kawada J, Kawabata R, Takahashi T, Fujita J, Hirao T, Shibata K, Makari Y, Iijima S, et al: NY-ESO-1 antibody as a novel tumour marker of gastric cancer. Br J Cancer 108: 1119-1125, 2013.

11. Middleton $\mathrm{CH}$, Irving W, Robertson JF, Murray A, Parsy-Kowalska CB, Macdonald IK, McElveen J, Allen J, Healey GF, Thomson BJ, et al: Serum autoantibody measurement for the detection of hepatocellular carcinoma. PLoS One 9: e103867, 2014.

12. Long YY, Wang Y, Huang QR, Zheng GS and Jiao SC: Measurement of serum antibodies against NY-ESO-1 by ELISA A guide for the treatment of specific immunotherapy for patients with advanced colorectal cancer. Exp Ther Med 8: 1279-1284, 2014.

13. Sobin LH, Gospodarowicz MK and Wittekind C: TNM Classification of Malignant Tumors. 7th edition. Oxford: Wiley-Blackwell, pp100-105, 2009.

14. Chen YT: Characterization of NY-ESO-1 and SSX gene families. Cancer Immun 3: 13, 2003.

15. Chen YT, Boyer AD, Viars CS, Tsang S, Old LJ and Arden KC: Genomic cloning and localization of CTAG, a gene encoding an autoimmunogenic cancer-testis antigen NY-ESO-1, to human chromosome Xq28. Cytogenet Cell Genet 79: 237-240, 1997.
16. Mackensen A, Meidenbauer N, Vogl S, Laumer M, Berger J and Andreesen R: Phase I study of adoptive T-cell therapy using antigen-specific CD8+ T cells for the treatment of patients with metastatic melanoma. J Clin Oncol 24: 5060-5069, 2006.

17. Uenaka A, Wada H, Isobe M, Saika T, Tsuji K, Sato E, Sato S, Noguchi Y, Kawabata R, Yasuda T, et al: T cell immunomonitoring and tumor responses in patients immunized with a complex of cholesterol-bearing hydrophobized pullulan (CHP) and NY-ESO-1 protein. Cancer Immun 19: 7:9, 2007.

18. Kakimi K, Isobe M, Uenaka A, Wada H, Sato E, Doki Y, Nakajima J, Seto Y, Yamatsuji T, Naomoto Y, et al: A phase I study of vaccination with NY-ESO-1f peptide mixed with Picibanil OK-432 and Montanide ISA-51 in patients with cancers expressing the NY-ESO-1 antigen. Int J Cancer 129: 2836-2846, 2011.

19. Oshima Y, Shimada H, Yajima S, Nanami T, Matsushita K, Nomura F, Kainuma O, Takiguchi N, Soda H, Ueda T, et al: NY-ESO-1 autoantibody as a tumor-specific biomarker for esophageal cancer: Screening in 1969 patients with various cancers. J Gastroenterol 51: 30-34, 2016.

20. Li M, Yuan YH, Han Y, Liu YX, Yan L, Wang Y and Gu J: Expression profile of cancer-testis genes in 121 human colorectal cancer tissue and adjacent normal tissue. Clin Cancer Res 11: 1809-1814, 2005.

21. Stockert E, Jäger E, Chen YT, Scanlan MJ, Gout I, Karbach J, Arand M, Knuth A and Old LJ: A survey of the humoral immune response of cancer patients to a panel of human tumor antigens. J Exp Med 187: 1349-1354, 1998

22. Yarbro JW, Page DL, Fielding LP, Partridge EE and Murphy GP American Joint committee on cancer prognostic factors consensus conference. Cancer 86: 2436-2446, 1999.

23. Ulanska J, Dziki A, Langner E and Wronski W: Risk factors in the recurrence of the colorectal cancer. Acta Chir Iugosl 49: 41-43, 2002. 